\title{
An experimental study to see the antihypertensive effects of gymnema sylvestre and acorus calamus in wistar rats and its comparison with amlodipine
}

\author{
Dheeraj Kumar Singh ${ }^{1}$, Narendra Kumar ${ }^{2}$, Anjula Sachan ${ }^{3}$, Preet Lakhani ${ }^{4}$, Sachin Tutu ${ }^{5}$, \\ Pratap Shankar6, Rajendra Nath7, Amod Kumar Sachan ${ }^{8}$, Rakesh Kumar Dixit ${ }^{9}$ \\ ${ }^{1}$ Junior Resident IIIrd year, ${ }^{2}$ Assistant Professor, ${ }^{3}$ Assistant Professor, Department of Pharmacology, HIMS, Mau, Ataria, \\ Sitapur. ${ }^{4,5}$ Junior Resident I/nd year, ${ }^{6}$ PhD Scholar, ${ }^{7,8,9}$ Professor, Department of Pharmacology, King George's Medical \\ University, Lucknow. U.P, India
}

\section{A B S T R A C T}

Background: The prevalence of obesity is increasing worldwide. Obesity has a direct correlation with insulin resistance and various cardiovascular diseases like hypertension, dyslipidaemia etc. Hypertension is considered as a major independent risk factor for coronary disease and stroke for all age, race \& sex groups. Gymnema sylvestre and Acorus calamus are two well known herbs of traditional system of medicine effective in various diseases. Aims and Objectives: The present study was designed to explore the antihypertensive effects of Gymnema sylvestre (GS) and Acorus calamus (AC), individually as well as in combination, in wistar rats. Materials and Methods: Female wistar rats, weighing between 150- $200 \mathrm{~g}$, were included in the study. They were divided into eight groups with six rats in each group. High Fat diet (HFD) was used to induce hypertension in all the groups except group 1 which was fed with normal rodent diet. Drugs were given to the rats by oral feeding cannula. Results: Feeding rats with HFD for 4 weeks lead to significant increase in the mean systolic blood pressure. Both Gymnema sylvestre and Acorus calamus significantly reduced the systolic blood pressure. Combination of both these (Gymnema sylvestre $200 \mathrm{mg} / \mathrm{kg}$ and Acorus calamus $200 \mathrm{mg} / \mathrm{kg}$ ) as well as Gymnema sylvestre $(200 \mathrm{mg} / \mathrm{kg})$ individually has an effect comparable to Amlodipine. Individual drugs had no significant effect on heart rate while the combination of these two drugs significantly reduced the heart rate. Conclusions: The present study concludes that extracts of Gymnema sylvestre and Acorus calamus has a significant antihypertensive action in rodent model of hypertension. Combination is found superior to the individual drugs.

Key words: Blood pressure, High fat diet, Extract, Obesity, Rats
Access this article online

\section{Website:}

http://nepjol.info/index.php/AJMS

DOI: 10.3126/ajms.v8i3.16778

E-ISSN: 2091-0576

P-ISSN: 2467-9100

\section{INTRODUCTION}

Hypertension is a well known risk factor for adverse cardiovascular outcomes. ${ }^{1}$ As the blood pressure rises above the normal levels, there is a gradual increase in the incidence of coronary disease, stroke as well as associated cardiovascular mortality. ${ }^{2,3}$ There are various established risk factors for development of primary (essential) hypertension like advancing age, race, obesity, family history, physical inactivity etc. ${ }^{4,5}$ Obesity is one of the main contributors to essential hypertension in humans. ${ }^{6}$ Obesity is considered as a complex, multi-factorial disease that is often associated with insulin resistance diabetes, hypertension and other cardiovascular diseases. According to Framingham Heart Study, obesity is directly responsible for around $78 \%$ of essential hypertension in men and $65 \%$ of essential hypertension in women. 
Hypercholesterolemia, diabetes, hypertension, obesity, and smoking are the five leading modifiable risk factors that are responsible for more than half of cardiovascular mortality. ${ }^{8}$ Although rates of hypertension treatment and control have improved over the past few years yet we have not achieved the full control over the disease. Recent researches have demonstrated the potential role of natural products to counteract hypertension and other chronic non-communicable diseases. Various-natural products \& their combinations may act in a synergistic way to increases their bioavailability and offering some added advantages over chemical treatments.

Gymnema sylvestre (commonly known as Gurmar in Hindi) is a valuable indigenous herb, belonging to the family "Asclepiadaceae". Traditionally, extract of the plant has been found useful in constipation, dyspepsia, jaundice, renal calculi, haemorrhoids, asthma, bronchitis, cardiopathy, menorrhea, leucoderma etc. ${ }^{9}$ Various animal and human studies have shown the role Gymnema sylvestre as an antidiabetic agent. ${ }^{10}$

Acorus calamus (commonly known as Bach in Hindi) is a semi-aquatic herbaceous plant belonging to family "Acoraceae". Extract of rhizomes is known to be used in traditional medicine to treat nervous disorders, appetite loss, chronic diarrhoea, dysentery, colic, indigestion, bronchitis, chest pain, intermittent fevers, rheumatism etc. Extract of plant has reported anti-hyperglycaemic activity in various studies. ${ }^{11}$

Although some of the studies have reported the hypolipidaemic and anti-adipogenic effects of these two herbs but we could not find any study that has been conducted to evaluate their anti-hypertensive effect. Hence, present study was designed to evaluate the antihypertensive effect of Gymnema sylvestre and Acorus Calamus, individually as well as in combination, and its comparison with standard drug Amlodipine.

\section{MATERIALS AND METHODS}

\section{Experimental Procedure}

The study was commenced after getting approval (Approval No. -Research project No. 69/IAEC/2015) by the Institutional Animal Ethics Committee (IAEC), King George's Medical University, Lucknow.

Adult healthy female wistar rats weighing 150- $200 \mathrm{~g}$ were procured from Indian Institute of Toxicology Research, Lucknow. They were kept at Institutional animal house (King George's Medical University, Lucknow) under standard conditions of temperature $\left(25 \pm 2^{\circ} \mathrm{C}\right)$, humidity
(55 \pm 05\%) and light-dark cycle controlled environment. Animals were given standard chow and free access to drinking water during the period of acclimatization.

Rats were divided randomly in eight groups with six rats in each group. During phase I on the study, at day 0, anthropometric variables, systolic blood pressure (SBP) and heart rate (HR) was recorded. Hypertension was induced in group 2 to 8 by feeding them on High Fat Diet (HFD) for 4 weeks while Group 1 (Normal Control) was fed on normal chow. HFD contained crude fat $25 \%$, crude protein $18 \%$, carbohydrate $44 \%$, fiber $13 \%$, moisture $8 \%$, Vitamins, minerals and other ingredients in appropriate quantity. It was provided by Bharat Science Solution Company, Lok Nagar, Unnao, Uttar Pradesh. At the end of $4^{\text {th }}$ week all the variables were recorded again.

During phase II of the study (from $5^{\text {th }}$ week to the end of $8^{\text {th }}$ week) group 1 was continued on normal chow, group 2 was kept on HFD while rest of the groups were given HFD along with respective drugs. Group 3 and 4 were given Gymnema sylvestre $100 \mathrm{mg} / \mathrm{kg}$ and $200 \mathrm{mg} / \mathrm{kg}$ respectively. Group 5 and 6 were given Acorus calamus $100 \mathrm{mg} / \mathrm{kg}$ and $200 \mathrm{mg} / \mathrm{kg}$ respectively. Combination of Gymnema sylvestre $200 \mathrm{mg} / \mathrm{kg}$ and Acorus calamus $200 \mathrm{mg} / \mathrm{kg}$ was given to group 7. Amlodipine $10 \mathrm{mg} / \mathrm{kg}$ was used as the standard drug in group 8. All the drugs were given as a suspension of distilled water through oral route by oral feeding cannula.

\section{Measurement of Systolic Blood Pressure}

Systolic Blood Pressure (SBP) and heart rate was measured with the help of NIBP controller machine (ML 125), AD Instruments (Australia) by using tail cuff method.

\section{Statistical Analysis}

Statistical analysis was carried out using SPSS Statistics 20 (Armonk, NY: IBM Corp.) Results were expressed as mean \pm standard error of mean (S.E.M.). Analysis of variance (ANOVA) followed by Dunnett's t-test and paired-t test was used to compare data. p-value $<0.05$ was considered statistically significant.

\section{RESULTS}

\section{Effect on Systolic Blood Pressure}

Application of ANOVA at Day 0 showed that all the groups were comparable as no significant difference was found among the groups $(F=0.735$, p value 0.64$)$ in terms of SBP. Groups were also found comparable to each other regarding body weight and BMI. On feeding groups 2 to 8 with High fat diet for 4 weeks, their body weight, Body mass index and SBP increased significantly from their baseline values and when they were compared to group 1 (Normal control) 
significant difference ( $\mathrm{p}$-value $<0.01$ ) was observed. After giving drugs to group 3 to 8 for next 4 weeks, significant changes were observed.

Paired t test was applied to compare the variables in individual groups at different time intervals (day 0 to wk 4, wk 4 to wk 8 and day 0 to wk 8). As compared to Day 0, SBP on wk 4 increased significantly ( $\mathrm{p}$ value $<0.01$ ) in all the groups on HFD (2 to 8). Both the drugs significantly decreased the value of SBP at wk 8 (Table 1). In drug group 4, 6, $7 \& 8$ values were found comparable to the baseline. At final evaluation at week 8 (as compared to group 2) SBP got maximally reduced in group 7 (38.1\%) followed by Group 8 (35.1\%), Group 4 (26.4\%) and Group $6(22.4 \%)$.

As shown in Table 2, ANOVA revealed a significant difference ( $\mathrm{p}$-value $<0.01$ ) among the groups at wk 8 . Dunnett's post hoc test (comparison with Group $2 \& 8$ ) showed significant decrease in all the Groups as compared to group 2 (disease control group). On comparing with group 8 (Amlodipine standard), no difference was found in group 4 \& 7 . This showed that Gymnema sylvestre $200 \mathrm{mg} / \mathrm{kg}$ and combination of Gymnema sylvestre $200 \mathrm{mg} / \mathrm{kg} \&$ Acorus calamus $200 \mathrm{mg} / \mathrm{kg}$ reduced SBP to a level comparable by Amlodipine Group.

\section{Effect on Heart Rate}

Feeding rats with HFD although increased the blood pressure significantly but no significant change was observed in the heart rate except in group 6 (Table $3 \& 4$ ). Giving drugs for next four weeks did not change the heart rate significantly in any group except in group 7 (Combination group) in which it was found significantly decreased.

\section{DISCUSSION}

The World Health organization has reported hypertension, or high blood pressure, as the leading cause of cardiovascular mortality. Chronically elevated blood pressure is a major risk factor for various cardiovascular complications including coronary artery disease, stroke, heart failure, chronic kidney disease, vision loss and peripheral vascular disease. ${ }^{12}$ Obesity, diabetes, dyslipidaemia, hypertension, and smoking are considered as the leading modifiable risk factors that are held responsible for more than half of cardiovascular mortality.

Obesity is a chronic, multi-factorial disease. Overweight or obesity can lead to various hazardous complications like insulin resistance, diabetes, dyslipidaemia, hypertension, gout, some cancers etc. The basic etiology behind

\begin{tabular}{|c|c|c|c|c|}
\hline Groups & Baseline & WK 4 & WK 8 & $\begin{array}{c}\text { Percentage change } \\
\text { at WK } 8 \text { as } \\
\text { compared to } \\
\text { Group } 2\end{array}$ \\
\hline Group 1 & $112.8 \pm 3.2$ & $113.6 \pm 4.2$ & $112.2 \pm 3.5$ & 34.2 \\
\hline Group 2 & $108.7 \pm 1.2$ & $162.0 \pm 2.3^{*}$ & $170.5 \pm 2.0 \$$ & - \\
\hline Group 3 & $108.8 \pm 6.4$ & $157.8 \pm 5.8^{*}$ & $136.3 \pm 3.5^{\# \$}$ & 20.1 \\
\hline Group 4 & $116.8 \pm 3.4$ & $162.3 \pm 2.3^{*}$ & $125.5 \pm 2.8^{\#}$ & 26.4 \\
\hline Group 5 & $113.8 \pm 3.4$ & $163.0 \pm 2.7^{*}$ & $154.2 \pm 3.5^{\# \$}$ & 9.6 \\
\hline Group 6 & $108.3 \pm 9.2$ & $151.3 \pm 7.8^{*}$ & $132.3 \pm 7.8$ & 22.4 \\
\hline Group 7 & $105.7 \pm 4.3$ & $154.8 \pm 4.7^{*}$ & $105.6 \pm 3.7^{\#}$ & 38.1 \\
\hline Group 8 & $119.2 \pm 7.7$ & $154.8 \pm 6.0^{*}$ & $110.7 \pm 3.7^{\#}$ & 35.1 \\
\hline
\end{tabular}

*Significant as compared to Baseline (Day o), "Significant as compared to week 4 , "Significant as compared to Baseline (Day o)

\begin{tabular}{|c|c|c|c|c|}
\hline \multirow[t]{2}{*}{$\mathbf{Y}$} & \multicolumn{2}{|c|}{$\begin{array}{c}\text { Group } 2 \\
\text { (Disease control) }\end{array}$} & \multicolumn{2}{|c|}{$\begin{array}{c}\text { Group } 8 \\
\text { (Amlodipine control) }\end{array}$} \\
\hline & $\begin{array}{c}\text { Mean } \\
\text { difference } \\
(\mathrm{Y}-\text { Group 2) }\end{array}$ & $p$-value & $\begin{array}{c}\text { Mean } \\
\text { difference } \\
(\mathrm{Y}-\text { Group 8) }\end{array}$ & $p$-value \\
\hline Group 1 & $-58.3^{*}$ & $<0.01$ & 1.5 & 1.00 \\
\hline Group 2 & - & - & $59.8^{*}$ & $<0.01$ \\
\hline Group 3 & $-34.2^{*}$ & $<0.01$ & $25.7^{\star}$ & $<0.01$ \\
\hline Group 4 & $-45.0^{*}$ & $<0.01$ & 14.8 & 0.08 \\
\hline Group 5 & $-16.3^{*}$ & 0.04 & $43.5^{*}$ & $<0.01$ \\
\hline Group 6 & $-38.2^{*}$ & $<0.01$ & $21.7^{*}$ & $<0.01$ \\
\hline Group 7 & $-65.0^{*}$ & $<0.01$ & -5.2 & 0.91 \\
\hline Group 8 & $-59.8^{*}$ & $<0.01$ & - & - \\
\hline
\end{tabular}

\begin{tabular}{|c|c|c|c|c|}
\hline Groups & Baseline & WK 4 & WK 8 & $\begin{array}{c}\text { Percentage } \\
\text { change at WK } \\
8 \text { as compared } \\
\text { to Group } 2\end{array}$ \\
\hline Group 1 & $328.0 \pm 10.9$ & $326.0 \pm 15.4$ & $335.5 \pm 11.0$ & 3.4 \\
\hline Group 2 & $322.8 \pm 6.0$ & $345.5 \pm 7.6$ & $347.5 \pm 9.2$ & - \\
\hline Group 3 & $312.3 \pm 5.0$ & $335.7 \pm 11.6$ & $335.3 \pm 11.6$ & 3.5 \\
\hline Group 4 & $324.2 \pm 12.9$ & $340.2 \pm 6.5$ & $324.0 \pm 9.5$ & 6.8 \\
\hline Group 5 & $340.3 \pm 16.2$ & $337.8 \pm 6.8$ & $327.8 \pm 13.1$ & 5.7 \\
\hline Group 6 & $304.8 \pm 7.4$ & $329.5 \pm 6.4^{*}$ & $329.2 \pm 12.1$ & 5.3 \\
\hline Group 7 & $313.3 \pm 14.4$ & $345.2 \pm 5.1$ & $295.2 \pm 5.9^{\#}$ & 15.1 \\
\hline Group 8 & $330.0 \pm 11.3$ & $334.2 \pm 7.1$ & $332.2 \pm 10.1$ & 4.4 \\
\hline
\end{tabular}

*Significant as compared to day o, "Significant as compared to week 4

obesity is the disparity between energy uptake and energy expenditure. HFD fed rats can act as a 'humanized' model for obesity and its related co-morbidities. ${ }^{13,14}$ In the present study obesity and hypertension was induced in rats by feeding them on diet rich in fats. Systolic blood pressure 


\begin{tabular}{|c|c|c|c|c|}
\hline \multirow[t]{2}{*}{$\mathbf{Y}$} & \multicolumn{2}{|c|}{$\begin{array}{c}\text { Group 2 } \\
\text { (Disease control) }\end{array}$} & \multicolumn{2}{|c|}{$\begin{array}{c}\text { Group } 8 \\
\text { (Amlodipine control) }\end{array}$} \\
\hline & $\begin{array}{c}\text { Mean } \\
\text { difference } \\
(\mathrm{Y}-\text { Group 2) }\end{array}$ & $\mathrm{p}$-value & $\begin{array}{c}\text { Mean } \\
\text { difference } \\
(\mathrm{Y}-\text { Group 8) }\end{array}$ & $p$-value \\
\hline Group 1 & -12.0 & 0.94 & 3.3 & 1.0 \\
\hline Group 2 & - & - & 15.3 & 0.84 \\
\hline Group 3 & -12.2 & 0.94 & 3.2 & 1.00 \\
\hline Group 4 & -23.5 & 0.46 & -8.2 & 0.99 \\
\hline Group 5 & -19.7 & 0.64 & -4.3 & 1.00 \\
\hline Group 6 & -18.3 & 0.70 & -3.0 & 1.00 \\
\hline Group 7 & $-52.3^{*}$ & 0.01 & -37.0 & 0.09 \\
\hline Group 8 & -15.3 & 0.84 & - & - \\
\hline
\end{tabular}

increased significantly in rats fed on HFD as compared to the normal control group.

From $4^{\text {th }}$ week onward group 2 to 8 were given HFD along with respective drugs. Assessment of SBP at the end of $8^{\text {th }}$ week showed that both the test dugs significantly reduced the SBP. These findings are supported by few studies conducted in the past. ${ }^{15-17}$ The effect of combination of Gymnema sylvestre (200mg/kg) \& Acorus calamus $(200 \mathrm{mg} / \mathrm{kg}$ ) as well as Gymnema sylvestre $200 \mathrm{mg} / \mathrm{kg}$ individually was found comparable to Amlodipine $10 \mathrm{mg} / \mathrm{kg}$. Combination was found superior to the individual drugs. None of the drug individually affected the heart rate but the combination of Gymnema sylvestre (200mg/kg) \& Acorus calamus (200mg/kg) significantly decreased the heart rate.

Extract of Gymnema is known to possess Gymnemic acids and Gurmarin. These active constituents have shown effective role in controlling hyperglycemia as well as obesity. Proper control of body weight has a direct correlation with systolic blood pressure. Antiadipogenic and hypolipidaemic activities of Gymnema sylvestre could be the direct or indirect mechanism of its antihypertensive action. On the other hand Acorus calamus, as shown by some studies, blocks the voltage gated calcium channels along with generation of nitric oxide and decreasing plasma renin activity. ${ }^{16,17}$

From the present study it can be concluded that Gymnema sylvestre $(200 \mathrm{mg} / \mathrm{kg})$ and combination of Gymnema sylvestre $(200 \mathrm{mg} / \mathrm{kg})$ and Acorus calamus $(200 \mathrm{mg} / \mathrm{kg})$ have a significant anti-hypertensive action comparable to that of Amlodipine $(10 \mathrm{mg} / \mathrm{kg})$ in HFD induced hypertensive rat model. The potential antihypertensive action of these herbs should be further checked on higher animals as well as on humans.
Note: Gymnema sylvestre and Acorus calamus are the well known herbal plants of traditional medicinal system. The extracts of both the plants are known to possess antidiabetic activity. Some of the studies have shown their hypolipidaemic activities. The present study shows that the extract of leaves of Gymnema sylvestre and rhizomes of Acorus calamus, when used in combination, can effectively control hypertension.

\section{REFERENCES}

1. Yusuf S, Hawken S, Ounpuu S, Dans T, Avezum A, Lanas $F$, et al. Effect of potentially modifiable risk factors associated with myocardial infarction in 52 countries (the INTERHEART study): Case control study. Lancet 2004; 364(9438):937-952.

2. Chobanian AV, Bakris GL, Black HR, Chusman WC, Green LA, Izzo JL, et al. National Heart, Lung, and Blood Institute Joint National Committee on Prevention, Detection, Evaluation, and Treatment of High Blood Pressure and National High Blood Pressure Education Program Coordinating Committee. The Seventh Report of the Joint National Committee on Prevention, Detection, Evaluation, and Treatment of High Blood Pressure: The JNC 7 report. JAMA 2003; 289:2560-2572.

3. Lewington S, Clarke R, Qizilbash N, Peto R and Collins R. Age specific relevance of usual blood pressure to vascular mortality: A metaanalysis of individual data for one million adults in 61 prospective studies. Lancet 2003; 361(9362):1060.

4. Forman JP, Stampfer MJ and Curhan GC. Diet and lifestyle risk factors associated with incident hypertension in women. JAMA 2009; 302(4):401-411.

5. Staessen JA, Wang J, Bianchi G and Birkenhäger WH. Essential hypertension. Lancet 2003; 361(9369):1629-1641.

6. Sonne-Holm S, Sørensen $\mathrm{TI}$, Jensen $\mathrm{G}$ and Schnohr P. Independent effects of weight change and attained body weight on prevalence of arterial hypertension in obese and nonobese men. BMJ 1989; 299(6702):767-770.

7. Kannel WB, Brand N, Skinner JJ, Dawber TR and McNamara PM. The relation of adiposity to blood pressure and development of hypertension: The Framingham Study. Ann Intern Med 1967;67(1):48-59.

8. Patel SA, Winkel M, Ali MK, Narayan KM and Mehta NK. Cardiovascular mortality associated with 5 leading risk factors: National and state preventable fractions estimated from survey data. Ann Intern Med 2015; 163(4):245-253.

9. Anis M, Sharma MP, and lqbal M. Herbal ethnomedicine of the Gwalior forest division in Madhya Pradesh, India, Pharmaceutical Biology 2000; 38(4):241-253.

10. Sugihara $Y$, Nojima $H$, Matsuda $H$, Murakami T, Yoshikawa $M$ and Kimura I. Antihyperglycemic effects of gymnemic acid IV, a compound derived from Gymnema sylvestre leaves in streptozotocin-diabetic mice. Journal of Asian Natural Products Research 2000;2 (4):321-327.

11. Prisilla $\mathrm{DH}$, Balamurugan $\mathrm{R}$ and Shah HR. Antidiabetic activity ofcmethanol extract of Acorus calamus in STZ induced diabetic rats. Asian Pac J Trop Biomed 2012;2(2):941-946.

12. Lackland, DT and Weber MA. Global burden of cardiovascular disease and stroke: Hypertension at the core. The Canadian journal of cardiology 2015; 31 (5):569-571.

13. Rosini TC, Da Silva ASR and Moraes CD. Diet-induced obesity: Rodent model for the study of obesity-related disorders. Rev Assoc Med Bras 2012; 58(3):383-387. 
14. Carroll JF, Zenebe WJ and Strange TB. Cardiovascular function in rat model of dietinduced obesity. Hypertension 2006; 48(1):65-72.

15. Kumar V, Bhandari U, Tripathi CD and Khanna G. Evaluation of antiobesity and cardioprotective effect of Gymnema sylvestre extract in murine model. Indian $\mathrm{J}$ Pharmacol 2012; 44(5):607-613.
16. Robertson TP, Hague D, Aaronson PI and Ward JPT. Voltageindependent calcium entry in hypoxic pulmonary vasoconstriction of intrapulmonary arteries of the rat. The journal of physiology 2000; 525(3):669-680.

17. Patel P, Vaghasiya J, Thakor A abd Jariwala J. Antihypertensive effect of rhizome part of Acorus calamus on renal artery occlusion induced hypertension in rats. Asian Pac J Trop Dis 2012; 2(1):6-10

\section{Authors Contribution:}

DKS- Concept and design of the study, reviewed the literature, collected data, statistically analyzed and interpreted manuscript preparation and critical revision of the manuscript; NK- Concept, literature search, review of literature; AS- Conceptualized study, statistical analysis manuscript preparation; PL- Review of literature, data acquisition; ST- Manuscript preparation and critical revision of the manuscript; PS- Review of literature, statistical analysis; RN- Review of literature, statistical analysis; AKS- Design of the study, manuscript review; RKD- Concept and design of the study, critical revision of the manuscript.

\section{Orcid ID:}

Dr. Dheeraj Kumar Singh*: http://orcid.org/0000-0002-7169-771X

Dr. Narendra Kumar:(i) http://orcid.org/0000-0003-3306-6519

Dr. Anjula Sachan:@ http://orcid.org/0000-0003-1842-2685

Dr. Preet Lakhani:@ http://orcid.org/0000-0002-1571-6226

Dr. Sachin Tutu: http://orcid.org/0000-0002-5939-3246

Dr. Pratap Shankar: $\mathrm{http}: / /$ orcid.org/0000-0002-7920-5214

Dr. Rajendra Nath: $h$ http://orcid.org/0000-0003-3818-6720

Dr. Amod Kumar Sachan: (1) http://orcid.org/0000-0002-2978-0990

Dr. Rakesh Kumar Dixit: (i) http://orcid.org/0000-0002-6037-0383 